\title{
POREMEĆAJI HODA U STARIJOJ DOBI
}

\author{
Jasminka Đelilović-Vranićl, Edina Đozićl, Merita Tirić-Čampara ${ }^{1}$, \\ Amina Nakičevićl, Edina Tanović ${ }^{2}$ \\ ${ }^{1}$ Neurološka klinika, Klinički centar univerziteta u Sarajevu, Sarajevo, Bosna i Hercegovina, \\ ${ }^{2}$ Klinika za fizikalnu medicinu i rehabilitaciju, Klinički centar univerziteta u Sarajevu, Sarajevo, \\ Bosna i Hercegovina \\ Autorica za korespondenciju: \\ Jasminka Đelilović-Vranić \\ jasminka.djelilovic@gmail.com
}

primljen: 2019, prihvaćen: 2019, objavljen: 2020.

\section{Apstrakt}

Poremećaji hoda i poremećaji ravnoteže uobičajeni su klinički problemi za starije osobe. Uzroci poremećaja hoda su individualni, često zbog fiziološkog procesa starenja i somatskih bolesti. Poremećaji hoda dovode do gubitka lične slobode, pada i povreda i rezultiraju značajnim smanjenjem kvaliteta života. Kod starijih osoba, kontrola statičke i dinamičke kontrole položaja i ritma je poremećena, što dovodi do izmijenjenog hoda, smanjuje se korak, povećava se širina hoda kako bi se održala ravnoteža, gornji dio tijela se savija prema naprijed da bi se održala ravnoteža, ruke se ne pomiču dok hodaju, hod je nepravilan, teže je započeti prve korake nakon sjedenja ili stajanja, kao i okretanja. Ako je moguće, najbolje je tretirati etiološki faktor, tj. osnovne bolesti, kao što su parkinsonizam, neki metabolički poremećaji itd. Treba voditi računa o nusefektima nekih lijekova, naročito antiparkinsonika, sedativa, hipnotika i antidepresiva. Također je potrebno uključiti i druge specijaliste, kao što su reumatolozi, fizijatri i fizioterapeuti, kao i internisti, kardiolozi i dijabetolozi. Kognitivne strategije također mogu biti korisne, na primjer usmjeravanje pažnje na svaki pojedinačni korak, a ne čin hodanja kao takav, svjesno pokušavajući napraviti pojedinačne velike korake, ili mentalno brojanje, kao i upotreba pomagala za hodanje.

Ključne riječi: poremećaji hoda, starija životna dob. 
Hod je visoko diferencirana funkcija, koja počinje od mozga. Ciklus hoda može se podijeliti na 2 različite faze.

1. Faza oslonca

2. Faza zamaha

Faza oslonca zauzima $60 \%$ ciklusa hoda, dok faza zamaha zauzima samo $40 \%(1)$.

Faza oslonca može se podijeliti u fazu pete /inicijalna faza/, fazu potpore i završnu fazu (2). I faza zamaha se može podijeliti na faze podizanja i savijanja nogu. Faza pete, također poznata kao početni kontakt, kratak je period koji počinje u trenutku kada se noga dotakne tla i prva je faza dvostrukog oslonca. Nakon toga ostatak stopala dotakne zemlju, a mišići rade kako bi se nosili sa silama koje prolaze kroz nogu. Ovo je poznato kao faza podrške. I na kraju, u fazi isključivanja, noga se odmiče od podloge - prvo peta, zatim prsti (1). Kada se stopalo odvojilo od podloge, noga se podigne i spremna je na fazu zamaha. U fazi zamaha, podignuta noga se pokreće naprijed. Ovo je ustvari momenat kada se napravi prvi korak. Zatim peta dotakne podlogu i čitav ciklus se ponavlja.

Normalan hod ima svoj obrazac, koji podrazumijeva sljedeće karakteristike:

- dužina i širina koraka

- frekvencija i trajanje koraka

- faza zamaha i faza oslonca

- trajanje dvostrukog oslonca

- regularnost i simetrija hodanja

- interakcija fleksora i ekstenzora kuka, koljena i skočnih zglobova s naizmjeničnim pokretima ruku i nogu

S druge strane, obrazac normalnog hodanja uključuje uspravan stav, koji zahtijeva ravnotežu prilikom hodanja, refleks uspravljanja, prisustvo posturalnih i potpornih refleksa, kao i reakciju spašavanja i odbrambenu reakciju u slučaju mogućeg pada (3). Ono što treba istaći jeste činjenica da čovjek treba pokret i započinjanje hoda kad god želi, ali je vrlo važno da to izvodi ritmično. Da bi se to obezbijedilo, potrebno je da više različitih dijelova ljudskog mozga bude uključeno u taj proces, a to su:

- piramidalni sistem i frontalni režanj velikog mozga

- ekstrapiramidalni sistem

- cerebelum

- vestibularni sistem

- vidni sistem

- periferni nervni sistem 
- koštano-mišićni sistem

Svaka od gore navedenih komponenti veoma je važna, kako za započinjanje hodanja tako i za njegovo pravilno obavljanje i održavanje. Kao što možemo zaključiti, hod i ravnoteža više se ne doživljavaju kao čisto motorni zadaci ili refleksi, već se posmatraju kao složena, senzorimotorna funkcija, koja uključuje i kognitivne i afektivne aspekte (4-8). U slučaju oštećenja bilo kojeg od njih, zbog raznih uzroka, imamo poremećaje hodanja i ravnoteže, što ponekad rezultira padovima i povredama. To dodatno komplicira stanje ljudi u starijoj životnoj dobi i remeti njihov kvalitet života. Uzroci koji dovode do poremećaja hoda dijele se na neurološke ili mišićno-skeletne uzroke (9).

Treba naglasiti da je piramidalni sistem vrlo važan, jer svi voljni impulsi, pa tako i započinjanje hoda, potiču iz kore velikog mozga, i to kroz aksone piramidalnog puta, jer na taj način frontalni režanj mozga kontroliše posturalne reflekse i početak hodanja.

Bazalne ganglije kontrolišu položaj i početak hodanja. Zato što je kontrola držanja tijela u Parkinsonovoj bolesti ozbiljno narušena, bazalne ganglije su dugo funkcionalno smatrane pretežno uključenim u motornoj kontroli, ali se sve više priznaje da igraju dodatne uloge u senzornoj obradi, spoznaji i ponašanju (10).

Mali mozak (cerebelum), zajedno s vestibularnim sistemom, jako je važan za održavanje ravnoteže prilikom hodanja. Mali mozak reguliše kognitivne i automatske procese držanja - hoda djelovanjem na cerebralni korteks preko talamokortikalne projekcije, kao i na moždano stablo (11). Vid jako važan za koordinaciju pokreta prilikom hodanja. Svi smo svjedoci da prilikom prelaska s dnevnog svjetla u zonu mraka, posebno početak hodanja, a i kasniji hod, otežan je i usporeniji, što govori o ulozi vida kao organa za proces hodanja.

Periferni nervni sistem koji ima zadatak da sprovodi površinski senzibilitet (osjećaj za dodir, bol i temperaturu), ali i duboki senzibilitet, također je vrlo bitan u procesu hodanja i održavanja pokreta i položaja tijela, i to na način da svojim aferentnim vlaknima donosi s periferije informacije koje se nakon "obrade" u mozgu eferentnim vlaknima vraćaju na periferiju i daju motornu inervaciju, prije svega mišićima, u smislu šta i koliko hodati ili koračati.

Sve ove strukture mozga jako su dobro povezane brojnim vezama i samo zajedno u koordinaciji omogućavaju normalan hod i održavanje ravnoteže. Kako bi se obezbijedio njihov nesmetani rad, nužna je optimalna vaskularizacija, koja treba biti konstantna, a moguće ju je održavati zahvaljujući mehanizmima autoregulacije koji postoje u mozgu. Ta optimalna količina krvi koju mozak treba da bi u potpunosti obavljao svoje funkcije jest 50-60 ml 
krvi na 100 g moždanog tkiva kada je srednji pritisak 8-24 kPh (raspon autoregulacije). U slučajevima kada iz raznih razloga taj nivo protoka padne na niže vrijednosti, dešava se poremećaj autoregulacije, što ima za posljedicu izmijenjenu funkciju pojedinih dijelova mozga, zavisno od toga u kojem se irigacionom području mozga dešava, a kasnije, ako taj deficit dotoka krvi traje duže, mogu nastati i strukturalne promjene u mozgu.

Krv u mozak donosi kiseonik i hranljive materije, prije svega glukozu kao izvor energije, i zbog toga je važno da mozak u svakom momentu dobiva dovoljnu količinu krvi, jer rezerve kiseonika u mozgu ne postoje. Posebno je na taj nedostatak osjetljiva siva supstanca mozga, što onda ima za posljedicu njenu izmijenjenu funkciju, a kasnije i strukturu parenhima mozga.

Iz svega do sada navedenog proizilazi da poremećaji hoda uopšte mogu biti posljedica oštećenja različitih dijelova nervnog sistema, ali i bolesti van nervnog sistema (drugih organa i organskih sistema), kao i kombinacije oštećenja i jednih i drugih. Zbog toga poremećaji hoda i ravnoteže postoje kod 1/3 osoba iznad 65 godina (12).

Individualnog su karaktera, često su rezultat fiziološkog procesa starenja i somatskih bolesti. Oni su uzrok ograničenog kretanja ovih osoba, uz nespretnost i ukupno slabiji kvalitet života, a često su uzrok padova i preloma kuka i različitog stepena invaliditeta. Poremećaji hoda i ravnoteže su među najčešćim uzrocima pada kod starijih odraslih $(13,14)$.

Senilni obrasci hoda zapravo mogu predstavljati ranu manifestaciju supkliničke bolesti, jer poremećaj korelira s povećanim rizikom od kardiovaskularnih bolesti, demencije, institucionalizacije i smrti (15).

Nutt i saradnici su poremećaj hoda hijerarhijski klasifikovali na niži, srednji i viši nivo poremećaja (16).

Niži nivo poremećaja - zbog oštećenja muskuloseletalnog sistema i perifernih živaca - dovodi do senzorne, vizuelne vestibularne ataksije.

Srednji nivo poremećaja hoda - uzrok je nastanka hemiplegije i paraplegije, cerebelarne ataksije i Parkinsonovog hoda.

Najviši nivo poremećaja hoda - kada je izražen poremećaj supkortikalne ili frontalne ravnoteže, s nemogućnošću početka šetnje i poremećajem frontalnog hodanja.

Poremećaji hoda dovode do gubitka lične slobode, pada i povreda i rezultiraju značajnim smanjenjem kvaliteta života (17).

U starijoj dobi se poremećaji hoda javljaju uobičajeno, jer je poremećena kontrola položaja i koordinacije pokreta tijela u cjelini. Snaga mišića i pokretljivost ruku i nogu mogu biti očuvani u 3. dobu, ali je poremećen ekvilibrij i 
interakcija mišića odgovornih za kontrolu položaja i koordinaciju hodanja te ravnoteža, i statička i dinamička.

Kod starijih osoba je poremećena statička i dinamička kontrole položaja i ritmike i nastaje redukcija hoda: korak je smanjen, širina hoda se povećava radi održavanja ravnoteže, gornji dio tijela povijen je prema naprijed, kako bi se očuvala ravnoteža, ruke se ne kreću prilikom hodanja, hod je iregularan, teže je početi prve korake nakon sjedenja ili ustajanja, ali i izvođenje pokreta okretanja.

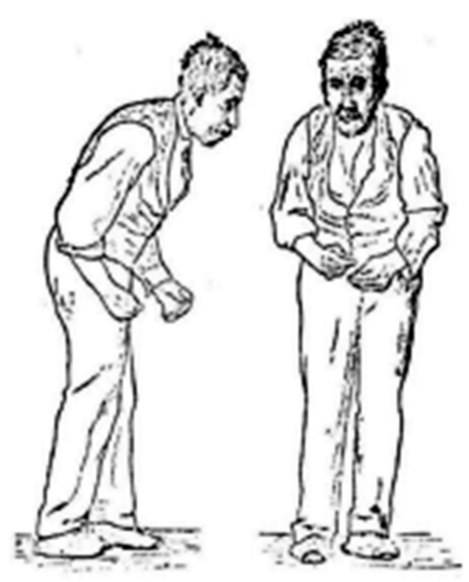

Slika 1. Tipično držanje osobe s Parkinsonovom bolešću. Ilustracija Parkinsonove bolesti od strane Sir Williama Richarda Gowersa iz priručnika o bolestima nervnog sistema iz 1886. god.

Različite bolesti u starosti pogađaju različite strukture mozga važne za pravilan hod, može ih biti i više. Senzorni podražaji - vidni, proprioceptivni i vestibularni slabe jer se smanjuje priliv s periferije, ali i njihova centralna obrada zbog starenja mozga.

Broj informacija s periferije starenjem se smanjuje posebno zbog smanjenja mehanoreceptora u vratnom dijelu kičme zbog degenerativnih spondiloartrotičnih promjena, manjeg ili većeg stepena izraženosti. Također uzrok mogu biti različite polineuropatije, koje su rezultat simetričnog oštećenja perifernih nerava zbog jako česte šećerne bolesti u toj dobi, ali mogu biti i posljedica dugotrajne upotrebe alkohola, malignoma, ali i toksičnih metaboličkih ili egzogenih, upalnih (poliradiculoneuritis) ili nutritivnih agenasa, kao deficita vitamina B12. 
Piramidalni put koji je odgovoran za započinjanje hodanja najčešće je oštećen vaskularnim akcidentima, moždanim udarom, što ima za posljedicu hemiparezu ili plegiju s oštećenjem moždanih živaca, a često može biti oštećen i različitim tumorskim procesima, kako primarnim tako i sekundarnim. Sve to ima za posljedicu hemiparetično spastičan hod (ili paraparetičan) $\mathrm{s}$ hodanjem na široj osnovi, uz nemogućnost savijanja u koljenima i kukovima te nemogućnosti odizanja noge od podloge, a često i sa zabacivanjem oštećene noge u polje prilikom hodanja, uz osjećaj zatezanja u njoj, ponekada i kočenja (18). Istu vrstu poremećaja hoda mogu izazvati i degenerativne promjene na vratnoj kičmi, kao što je cervikalna mijelopatija zbog spondiloze i spondiloartroze te hidrocefalusi normalnog pritiska.

Oštećenje bazalnih ganglija mozga i ostalih struktura ekstrapiramidalnog sistema ima za posljedicu nastanak parkinsonskog hoda sa sitnim koracima s anteropulzijom, otežanim okretanjem u mjestu, ljepljivim koracima - mogući su padovi i povrede. Ova vrsta hoda može nekada biti posljedica i upotrebe nekih lijekova.

Oštećenja malog mozga moguća su zbog: vaskularnih incidenata u smislu moždanih udara, zatim degeneracije koja se dešava kod hipotireoze, kod malignih bolesti, ali i upotrebe etanola, različitih sedativa i fenitoina. Sve to ima za posljedicu ataksični hod - na širokoj osnovi, kako bi se održala ravnoteža.

Brojna su oštećenja koštano-mišićnog sistema u starijoj dobi, a uzrokovana su najčešće reumatskim procesima iz mladosti ili degenerativnim ortopedskim u kasnijoj dobi, uz vrlo često osteoporozu različitog stepena i razrjeđenje koštane mase. To ima za posljedicu povećan broj fraktura i bez padova, a posebno prilikom padova u ovoj dobi. Kao posljedica ovih degenerativnih promjena na kukovima javlja se gegav (patkast) hod - kada u hodu osoba prebacuje težinu tijela s jednog na drugi kuk, uz oslonac - pomagalo kako bi održala ravnotežu.

U slučaju oštećenja živaca na nogama, bilo traumatski ili zbog degenerativnih promjena u donjem dijelu kičmenog stuba, nastaje hod s cirkumdukcijom - nemogućnost savijanja u koljenu uz zabacivanje u polje, kako bi se prevazišao problem i osjećaj duže noge na toj strani.

\section{Kako liječiti poremećaje hoda}

Najbolje je ako ih je moguće liječiti etiološki, tj. liječeći osnovno oboljenje koje je dovelo do poremećaja hoda. To je moguće kod parkinsonizma, zatim kod nekih metaboličkih poremećaja, kao što je funikularna mijeloza, gdje nadomještanje vitamina B12 rješava problem, zatim kod različitih 
polineuropatija, cervikalne mijelopatije, uz pomoć drugih specijalista, prije svega reumatologa, fizijatara i fizioterapeuta te internista, kardiologa i dijabetologa. Nužno je vršiti čest nadzor nad vrijednostima krvnog pritiska i šećera u krvi, jer pad i jednih i drugih vrijednosti može imati za posljedicu različita kolapsna stanja i smetnje hoda i ne tako rijetke padove. Obično se koriste vježbe koje pojačavaju snagu mišića, kao i koordinacioni trening koji može poboljšati uobičajenu i maksimalnu brzinu kretanja starije osobe (19). Također je potrebna stalna podrška i stalno ohrabrivanje uz bodrenje i psihoterapiju zbog čega je jako važan kognitivni potencijal, koji treba koliko je moguće više sačuvati.

Pomagala za hodanje, kao što su hodalice s četiri točka i s kočnicama, mogu biti od pomoći (štap, kišobran itd.). Za poboljšanje balansa i sprečavanje padova koristi se nova tehnika upotrebe štapa koji projicira lasersku liniju na podu kod pacijenata s Parkinsonovom bolešću. Kognitivne strategije mogu također biti korisne, kao što je obraćanje pažnje na svaki pojedinačni korak, a ne čin hodanja kao takav, svjesno pokušavajući napraviti pojedinačne velike korake (21). Također je neophodno prilagoditi okolinu - uslove u stanu za bolji oslonac, razmještanje namještaja itd.

Ono što je posebno važno, radi prevencije poremećaja hoda i mogućih padova, u starijoj dobi, treba obratiti pažnju na nusefekte pojedinih lijekova (posebno antiparkinsonika, sedativa, hipnotika, antidepresiva) koje starije osobe često uzimaju, na njihove međusobne interakcije i zbog toga bi bilo jako važno broj lijekova u starijoj dobi svesti na najmanju moguću mjeru.

Isto tako jako je važno, uz stalni fizički, provoditi i mentalni trening kod ovih osoba, kako bi se spriječila pojava padova i unaprijedio ukupni kvalitet života.

Istraživanja u protekle dvije decenije pokazala su snažne efekte kognicije na hod (22), uključujući ulogu brzine hoda i poremećaja hoda u starijoj dobi kao indikatora za budući razvoj demencije i očekivanog trajanja života $(23,24)$.

\section{Reference}

1. Loudon J, et al. The clinical orthopedic assessment guide. 2nd ed. Kansas: Human Kinetics, 2008. p. 395-408.

2. Shultz SJ, et al. Examination of musculoskeletal injuries. 2nd ed. North Carolina: Human Kinetics, 2005. p. 55-60.

3. Xu B, Yan T, Yang Y, Ou R, Huang S. Effect of normal-walking-pattern-based functional electrical stimulation on gait of the lower extremity in subjects with ischemic stroke: A self controlled study. NeuroRehabilitation. 2016;38(2):163-9.

4. Montero-Odasso M, Verghese J, Beauchet O, Hausdorff JM. Gait and cognition: a complementary approach to understanding brain function and the risk of falling. J Am Geriatr Soc. 2012;60:2127-36. 
5. Amboni M, Barone P, Hausdorff JM. Cognitive contributions to gait and falls: evidence and implications. Mov Disord. 2013 in press.

6. Mirelman A, Herman T, Brozgol M, et al. Executive function and falls in older adults: new findings from a five-year prospective study link fall risk to cognition. PLoS One. 2012; 7:e40297.

7. Lord S, Galna B, Rochester L. Moving forward on gait measurement: towards a more refined approach. Mov Disord. 2013 in press.

8. Rosso AL, Studenski SA, Chen WG, et al. Aging, the central nervous system, and mobility. J Gerontol A Biol Sci Med Sci. 2013.

9. Malanga G, Delisa JA. Section One: Clinical Observation. Office of rehabilitation Research and Development No Date. http://www.rehab.research.va.gov/mono/gait/ malanga.pdf (pristupljeno 6. 2. 2010).

10. Bloem BR, Valkenburg VV, Slabbekoorn M, van Dijk JG. The multiple tasks test. Strategies in Parkinson's disease. Exp Brain Res. 2001;137:478-86.

11. Takakusaki K. Functional Neuroanatomy for Posture and Gait Control. J Mov Disord. 2017;10(1):1-17.

12. Centers for Disease Control and Prevention. Prevalence and most common causes of disability among adults - United States, 2005. MMWR Morb Mortal Wkly Rep. 2009;58(16):421-6.

13. Rubenstein LZ, Josephson KR. The epidemiology of falls and syncope. Clin Geriat Med. 2002;18(2):141-58.

14. Rubenstein LZ, Josephson KR. Falls and their prevention in elderly people: what does the evidence show? Med Clin North Am. 2006;90(5):807-24.

15. Verghese J, LeValley A, Hall CB, Katz MJ, Ambrose AF, Lipton RB. Epidemiology of gait disorders in community-residing older adults. J Am Geriatr Soc. 2006;54(2):255-61.

16. Nutt JG, Marsden CD, Thompson PD. Human walking and higher-level gait disorders, particularly in the elderly. Neurology. 1993;43(2):268-79.

17. Pirker W, Katzenschlager R. Gait disorders in adults and the elderly. Wien Klin Wochenschr. 2017;129(3):81-95.

18. Sheffler LR, Chae J. Hemiparetic Gait. Phys Med Rehabil Clin N Am. 2015;26(4):611-23.

19. Hortobagyi T, Lesinski M, Gabler M, VanSwearingen JM, Malatesta D, Granacher U. Effects of three types of exercise interventions on healthy old adults' gait speed: A systematic review and meta-analysis. Sports Med. 2015;45(12):1627-43.

20. Donovan S, Lim C, Diaz N, Browner N, Rose P, Sudarsky LR, et al. Laserlight cues for gait freezing in Parkinson's disease: an open-label study. Parkinsonism Relat Disord. 2011;17(4):240-5. doi: 10.1016/j.parkreldis.2010.08.010.

21. Nonnekes J, Snijders AH, Nutt JG, Deuschl G, Giladi N, Bloem BR. Freezing of gait: a practical approach to management. Lancet Neurol. 2015;14(7):768-78.

22. Snijders AH, van de Warrenburg BP, Giladi N, Bloem BR. Neurological gait disorders in elderly people: clinical approach and classification. Lancet Neurol. 2007;6(1):63-74.

23. Studenski S, Perera S, Patel K, Rosano C, Faulkner K, Inzitari M, et al. Gait speed and survival in older adults. JAMA. 2011;305(1):50-8.

24. Verghese J, Annweiler C, Ayers E, Barzilai N, Beauchet O, Bennett DA, et al. Motoric cognitive risk syndrome: multicountry prevalence and dementia risk. Neurology. 2014;83(8):718-26. 


\title{
GAIT AND BALANCE DISORDERS IN OLDER ADULTS
}

\begin{abstract}
The causes of gait disturbances are individual, often due to the physiological process of aging and somatic diseases. Gait disorders lead to a loss of personal freedom, falls and injuries and result in a marked reduction in the quality of life. In older people, the control of static and dynamic control of position and rhythm is disturbed, which leads to an alternate walk, pace is reduced, the spread of feet increases to maintain balance, the upper part of the body is bent forward in order to maintain balance, the hands do not move while walking, the walk is irregular, it is more difficult to start the first steps after sitting or standing, and turning also becomes more difficult. If possible, it is best to treat the etiological factor ie, the underlying diseases as parkinsonism, some metabolic disorders etc. In order to prevent walking disturbances and possible falls in the elderly special attention should be paid to the side effects of certain drugs, especially antiparkinsonics, sedatives, hypnotics, and antidepressants. It is also necessary to include other specialties such as rheumatologists, physiatrists and physiotherapists, as well as internists, cardiologists and diabetics. Cognitive strategies may also be helpful, such as directing one's attention to each individual step rather than the act of walking as such, consciously attempting to make individual large steps or mentally counting, as well as walking aids.
\end{abstract}

Keywords: walking disorders, older age. 